\title{
ARMAZENAMENTO REFRIGERADO DE BANANA'PRATA ANÃ' PROVENIENTE DE CACHOS COM 16, 18 E 20 SEMANAS
}

\author{
Refrigerated storage of 'Prata Anã' banana originating from 16, 18 e 20 week-old bunches
}

\author{
Ramilo Nogueira Martins'1, Mário Sérgio Carvalho Dias², \\ Eduardo Valério de Barros Vilas Boas ${ }^{3}$, Leandra Oliveira Santos ${ }^{4}$
}

\begin{abstract}
RESUMO
Conduziu-se este trabalho, com o objetivo de verificar a influência da temperatura de refrigeração e idade do cacho sobre a conservação e qualidade pós-colheita da banana 'Prata Anã', produzida no Norte de Minas Gerais, visando a exportação. Utilizaramse frutos de bananeira 'Prata Anã' provenientes do município de Nova Porteirinha, MG. A colheita foi realizada na $16^{\mathrm{a}}, 18^{\mathrm{a}}$ e $20^{\mathrm{a}}$ semanas após a emissão floral. Dos cachos colhidos, utilizou-se às segundas pencas, separadas em buquês com 5 frutos, lavados e pesados $(18 \mathrm{~kg})$. Em seguida, os frutos foram revestidos com embalagens de polietileno de baixa densidade, com 50m de espessura, sob vácuo parcial, acondicionados em caixas de papelão e distribuídos em paletes. Depois de embalados e paletizados, os frutos foram transportados para a EPAMIG/CTNM, onde foram armazenados em câmaras de refrigeração $\left(10\right.$ e $\left.12^{\circ} \mathrm{C}\right)$ e umidade relativa de $95 \%$, por um período de 35 dias, sendo analisados antes e após a refrigeração. O armazenamento de bananas 'Prata Anã', provenientes de cachos com 16, 18 e 20 semanas, por 35 dias a temperaturas de 10 e $12^{\circ} \mathrm{C}$, não promoveu "chilling" nos frutos. A temperatura de $10^{\circ} \mathrm{C}$ foi mais eficaz em prevenir a evolução da coloração da casca de bananas provenientes de cachos com 18 semanas, que à temperatura de $12^{\circ} \mathrm{C}$, enquanto as temperaturas de 10 e $12^{\circ} \mathrm{C}$ foram igualmente eficientes na contenção da mudança de cor de bananas provenientes de cachos com 16 semanas. Frutos provenientes de cachos com 20 semanas amadureceram desuniformemente, ao longo do armazenamento refrigerado.
\end{abstract}

Termos para indexação: Temperatura de refrigeração, idade de cacho.

\section{ABSTRACT}

This work had, as objective, to verify the influence of refrigeration temperature and bunch age on the conservation and postharvest quality of the 'Prata Anã' banana produced in the North of Minas Gerais, looking towards exportation. 'Prata Anã' banana tree fruits were used originating from the municipal district of Nova Porteirinha, MG. The crop was harvested in the 16th, 18th and 20th weeks after the floral emission. From the clusters picked, the second bunches was used, separated in clusters with 5 fruits, washed and weighed $(18 \mathrm{~kg})$. Soon after, the fruits were wrapped with polyethylene packing of low density with $50 \mathrm{~mm}$ of thickness under partial vacuum, conditioned in cardboard boxes and distributed on palets. After being wrapped and put on paletes, the fruits were transported to EPAMIG/CTNM, where they were stored in refrigeration chambers at 10 and $12^{\circ} \mathrm{C}$ with a relative humidity of $95 \%$ for a period of 35 days, being analyzed before and after the refrigeration. The storage of 'Prata Anã' bananas, coming from 16, 18 and 20 week-old bunches, for 35 days at temperatures of 10 and $12^{\circ} \mathrm{C}$ of did not promote "chilling injury" in the fruits. The $10^{\circ} \mathrm{C}$ temperature was more effective in preventing the evolution of the coloration of the peel of bananas coming from 18 week-old bunches than the $12^{\circ} \mathrm{C}$ temperature, while temperatures of 10 and $12^{\circ} \mathrm{C}$ were equally efficient in the contention of the change of color of bananas coming from 16 week-old bunches. Fruits coming from 20 week-old bunches matured non-uniformly during refrigerated storage.

Index terms: Refrigeration, bunch age.

(Recebido em 9 de agosto de 2005 e aprovado em 31 de outubro de 2006)

\section{INTRODUÇÃO}

A banana é um fruto climatérico de origem tropical e, como tal, está sujeita a danos pelo resfriamento (chilling), desordem fisiológica observada após a exposição dos frutos a baixas temperaturas, resultando na redução de sua qualidade, promovendo, principalmente, escurecimento da casca, baixa taxa de conversão de amido a açúcares, perda de sabor, aroma e brilho (VILAS-BOAS et al., 2001).

O armazenamento refrigerado consiste no principal meio de conservação dos vegetais, podendo ser aliado a outras técnicas de conservação. Entretanto, frutos sensíveis ao "chilling" devem ser armazenados sob temperaturas acima das mínimas de segurança, ou seja, que não promovam a desordem fisiológica. Bananas 'Prata

\footnotetext{
'Engenheiro Agrônomo, Doutorando - Departamento de Tecnologia - Universidade Estadual de São Paulo/UNESP - Campus de Jaboticabal - 14870 -000 Jaboticabal, SP - ramilomartins@yahoo.com.br

'Engenheiro Agrônomo, Doutor, Pesquisador - Empresa Agropecuária de Minas Gerais/EPAMIG - Rodovia MGT 122, Km 155, Zona Rural - Cx. P. 12 39525-000 - Nova Porteirinha, MG - mariodias@epamig.br

${ }^{3}$ Engenheiro Agrônomo, Doutor, Professor - Departamento de Ciências dos Alimentos/DCA - Universidade Federal de Lavras/UFLA - Cx. P. 3037 37200-000 - Lavras, MG - evbvboas@ufla.br

${ }^{4}$ Mestranda - Departamento de Tecnologia - Universidade Estadual de São Paulo/UNESP - Campus de Jaboticabal - 14870-000 - Jaboticabal, SP _ leandraoli@yahoo.com.br
} 
Anã' armazenadas a temperaturas abaixo de $12^{\circ} \mathrm{C}$, por 2 semanas, desenvolveram "chilling" (LIMA et al., 2001). Não obstante, a sensibilidade ao frio depende do binômio tempo x temperatura, bem como da cultivar e fatores précolheita, sendo que a temperatura limite para a ocorrência de "chilling" em diferentes cultivares de banana varia, normalmente, de 10 a $14^{\circ} \mathrm{C}$, podendo, entretanto bananas 'da Terra' serem armazenadas a $7,2^{\circ} \mathrm{C}$ por 7 dias, sem sintomas visíveis da desordem fisiológica (MORRELLI et al., 2003; WILLS, 1990).

Parte das perdas de produção ocorrem, principalmente, na colheita. Para minimizá-las e preservar as características originais dos frutos, a colheita deve ser realizada em momento oportuno. De modo geral, considerase que os frutos devam ser colhidos tanto mais imaturos quanto mais distantes estiverem do mercado consumidor, porém, sempre depois de fisiologicamente maturos (CANCIAN \& CARVALHO, 1980).

De todos os critérios utilizados para determinar o ponto de colheita, os mais utilizados são: desaparecimento da angulosidade dos frutos, dias após a emissão da inflorescência e diâmetro do fruto central da segunda penca (LICHTEMBERG, 2001). A colheita precoce permite a extensão da vida-de-prateleira dos frutos, embora possa comprometer sua qualidade final. Bananas 'Prata', provenientes de cachos colhidos a partir de 105 dias, apresentam características que garantem a extensão de sua vida pós-colheita, bem como o amadurecimento normal (AYUB, 1990; SANTOS \& CHITARRA, 1998).

Visto que a falta de informações sobre o comportamento dos cultivares brasileiros limita a aplicação de técnicas de conservação, objetivou-se, com o presente trabalho, verificar a influência da temperatura de refrigeração e idade do cacho sobre a conservação e qualidade pós-colheita da banana 'Prata Anã', produzida no Norte de Minas Gerais, visando a exportação.

\section{MATERIAL E MÉTODOS}

Foram utilizadas bananas 'Prata Anã', provenientes de Nova Porteirinha, Norte de Minas Gerais, em uma área de produção a uma altitude de $520 \mathrm{~m}$. As frutas foram colhidas na $16^{\mathrm{a}}, 18^{\mathrm{a}}$ e $20^{\mathrm{a}}$ semana após a inflorescência. O trabalho de campo consistiu em selecionar e colher os cachos que não apresentassem danos nas frutas. Após a colheita, os cachos foram levados via cabo aéreo para a casa de embalagem, onde se realizou o despencamento e a seleção de buquês da segunda penca, com base no calibre do fruto. Como o calibre do fruto está interativamente relacionado com a idade do cacho, adotou-se, neste trabalho, uma faixa de calibre para que frutos das diferentes idades pudessem ser utilizados. Para isso, as pencas foram divididas em buquês de cinco frutos, e, utilizando um calibrador bananeiro fixo, selecionaram-se os buquês com o fruto central apresentando de 38 a 48 graus, bananeiros (30,16 a 38,10 $\mathrm{mm}$ de diâmetro). Em tanques, os buquês foram tratados com sulfato de alumínio, lavados com água e detergente objetivando o estancamento do látex e limpeza dos frutos. A seguir, os buquês foram acondicionados em caixas de papelão, com capacidade para $18 \mathrm{~kg}$, revestidas com embalagens de polietileno de baixa densidade de $50 \mathrm{~mm}$, lacrados após a retirada parcial do ar, e paletizados de acordo a idade. Depois de embaladas e paletizadas, as frutas foram transportadas para a EPAMIG/CTNM, onde foram feitas três subdivisões para cada uma das três idades de frutas, sendo a primeira amostra imediatamente caracterizada quanto às análises físicas e químicas e as duas restantes armazenadas em câmaras de refrigeração, a $10 \pm 1^{\circ} \mathrm{C}$ e $12 \pm 1^{\circ} \mathrm{C}$, e UR $=90 \pm 5 \%$, por um período de 35 dias. Realizou-se o experimento seguindo um delineamento inteiramente casualizado, em esquema fatorial $(3 \times 2+3)$, testando-se, respectivamente, três idades de frutos (16, 18 e 20 semanas), duas temperaturas (10 e $12^{\circ} \mathrm{C}$ ) e três tratamentos controle referente aos frutos recém-colhidos com 16, 18 e 20 semanas. Assim, testaramse nove tratamentos, os quais se apresentaram com quatro repetições. Cada unidade experimental foi constituída por quatro buquês com cinco frutos, totalizando vinte frutos.

Análises: "Chilling" - Foram feitas avaliações visuais quanto o aparecimento do "chilling" após a retirada dos frutos das câmaras de refrigeração. As avaliações visuais se basearam na determinação de manchas escuras na casca dos frutos. Coloração - Para avaliar a eficácia dos tratamentos, determinou-se a coloração da casca, antes e após 35 dias de refrigeração, através da atribuição de notas (Figura 1).

\begin{tabular}{|cl|}
\hline Notas & \multicolumn{1}{c|}{ Coloração da casca } \\
\hline 1 & Totalmente verde \\
2 & Verde com traço amarelo \\
3 & Mais verde que amarelo \\
4 & Mais amarelo que verde \\
5 & Amarelo com pontas verdes \\
6 & Totalmente amarelo \\
7 & Amarelo com leves manchas marrons \\
\hline
\end{tabular}

FIGURA 1 - Notas de coloração da casca de bananas. Fonte: CSIRO (1972), citado por Wills et al. (1998). 
Relação polpa/casca - Obtida pela pesagem individual da polpa e casca dos frutos, com auxílio de uma balança semi-analítica; Firmeza da polpa - Foi utilizado um penetrômetro de mão marca TR, modelo 327 , com ponta de $8 \mathrm{~mm}$ de diâmetro, adaptada a um suporte com alavanca e bancada, marca Ferrari e as medidas foram tomadas na região central dos frutos descascados. Os resultados foram expressos em Newton (N); Amido - foi extraído e doseado pelo método de Somoghy, adaptado por Nelson (1944), e expresso em \% na polpa fresca; Açúcares solúveis totais (AST) - Determinados pelo método de antrona (DISCHE, 1962), sendo os resultados expressos $\%$ na polpa fresca; Sólidos solúveis totais (SST) - Obtidos por refratometria, utilizando o refratômetro manual (marca ATAGO, modelo N-1E). A determinação foi realizada através de metodologia descrita em AOAC (1992) e os resultados expressos em \% na polpa fresca; $\mathrm{pH}$ : Determinado através de pHmetro digital (marca TECNAL), de acordo com a metodologia descrita em AOAC (1992); Acidez titulável (AT): determinada por titulometria, sendo a titulação realizada conforme os métodos descritos por AOAC (1992); sendo os resultados expressos em \% na polpa fresca, considerando-se o ácido málico como o predominante; Análise estatística: os dados obtidos foram submetidos à análise de variância, por meio do teste $\mathrm{F}$, e as médias foram comparadas mediante o teste de Tukey, em nível de $5 \%$ de probabilidade. Para o teste Tukey,à medida que as fontes de variação idade de fruto e temperatura de armazenamento demonstraram-se significativos na análise de variância, foram considerados os efeitos isolados da idade do fruto, dentro do tratamento controle e armazenados a 10 e $12^{\circ} \mathrm{C}$; e os efeitos isolados do tratamento controle e armazenados 10 e $12^{\circ} \mathrm{C}$, dentre os frutos colhidos com 16, 18 e 20 semanas. Quando a análise de variância indicou efeito significativo para interação idade de fruto x temperatura de armazenamento, procedeu-se ao teste de média concomitante para os dois efeitos isolados, anteriormente indicados.

\section{RESULTADOS E DISCUSSÃO}

“Chilling” - Bananas 'Prata Anã', armazenadas por 35 dias às temperaturas de $10 \mathrm{e} 12^{\circ} \mathrm{C}$, provenientes de cachos com 16, 18 e 20 semanas não apresentaram sintomas de "chilling", na saída da câmara fria. Morrelli (2003) e Wills (1990) observaram variações na sensibilidade ao "chilling", em função da cultivar e tempo de exposição de bananas às temperaturas de armazenamento. Os autores, embora não tenham trabalhado com banana 'Prata Anã', verificaram que a temperatura mínima de segurança variou de $7,2^{\circ} \mathrm{C}$ a $14^{\circ} \mathrm{C}$, dependendo da cultivar. Lima et al. (2001) determinaram, ao contrário do observado no presente trabalho, que a temperatura mínima de segurança para banana 'Prata Anã' era de $12^{\circ} \mathrm{C}$.

Coloração - Os frutos controle, apresentaram índice de coloração semelhante, independentemente de serem provenientes de cachos com 16, 18 e 20 semanas. A temperatura de $10^{\circ} \mathrm{C}$ foi eficaz na manutenção do índice de coloração de frutos de 16 semanas e frutos de 18 semanas, ao longo do armazenamento refrigerado. Já a temperatura de $12^{\circ} \mathrm{C}$ foi eficiente na prevenção da mudança de cor apenas dos frutos de 16 semanas (Tabela 1).

TABELA 1 - Notas de coloração da casca de bananas 'Prata Anã', provenientes de cachos com 16, 18 e 20 semanas, após a colheita (controle) e armazenadas por 35 dias sob refrigeração.

\begin{tabular}{lccc}
\hline $\begin{array}{c}\text { Armazenamento } \\
\text { refrigerado }\end{array}$ & \multicolumn{3}{c}{ Idade dos cachos (semanas) } \\
\cline { 2 - 4 } $\begin{array}{c}\text { Controle (frutos } \\
\text { recém-colhidos) }\end{array}$ & $2(100 \%)$ & $2(100 \%)$ & $2(100 \%)$ \\
\hline & & $\mathbf{1 8}$ & $\mathbf{2 0}$ \\
35 dias a $10^{\circ} \mathrm{C}$ & $2(100 \%)$ & $2(100 \%)$ & $\begin{array}{l}3(30 \%) \\
4(40 \%) \\
5(30 \%)\end{array}$ \\
& & & $3(10 \%)$ \\
35 dias a $12^{\circ} \mathrm{C}$ & $2(100 \%)$ & $3(100 \%)$ & $\begin{array}{l}4(30 \%) \\
5(60 \%)\end{array}$ \\
\hline
\end{tabular}

Obs: Os números entre parênteses indicam a proporção de frutos em cada estádio de coloração.

Frutos de 20 semanas mostraram-se em estádio mais avançado de maturação, baseado na coloração da casca, que frutos e 16 semanas e frutos de 18 semanas, após 35 dias de armazenamento refrigerado, independentemente da temperatura. Além disso, observou-se desuniformidade na coloração da casca desses frutos. Frutos de 16 semanas, armazenados a $10^{\circ} \mathrm{C}$ e $12^{\circ} \mathrm{C}$ e frutos de 18 semanas, resfriados a $10^{\circ} \mathrm{C}$ mantiveram, após refrigeração, o mesmo grau de coloração que apresentavam antes de serem armazenados. Já os frutos de 18 semanas, armazenados a $12^{\circ} \mathrm{C}$ apresentavam-se em estádio mais avançado de maturação que os frutos controle após o armazenamento refrigerado.

Santos \& Chitarra (1998) observaram que quanto mais precoce a colheita mais tardia são as mudanças na coloração da casca de bananas 'Prata'. Os dados observados no presente trabalho são coerentes com as observações de Santos \& Chitarra (1998). De acordo com Lima et al. (2001), o amadurecimento de banana 'Prata Anã' 
é retardado, mas não influenciado negativamente por temperaturas iguais ou superiores a $12^{\circ} \mathrm{C}$.

Relação polpa/casca - A relação polpa/casca foi influenciada apenas pelo fator idade do cacho (Tabela 2).

TABELA 2 - Médias de relação polpa/casca de bananas 'Prata Anã', em função da idade do cacho independente do armazenamento sob refrigeração.

\begin{tabular}{cc}
\hline Idade de cacho (semanas) & $\begin{array}{c}\text { Médias } \\
\text { Relação Polpa/Casca }\end{array}$ \\
\hline 20 & $1,572 \mathrm{a}$ \\
18 & $1,292 \mathrm{~b}$ \\
16 & $1,220 \mathrm{~b}$ \\
\hline
\end{tabular}

Médias seguidas da mesma letra são iguais entre si pelo teste Tukey, ao nível de significância de 5\%.

Os frutos provenientes de cachos com 20 semanas apresentaram relação polpa/casca superior àqueles provenientes de cachos com 16 e 18 semanas. A relação polpa/casca, que obteve-se neste trabalho foi em média de 1,22 e 1,29 para frutos de 16 semanas e frutos de 18 semanas, ambos grupos estando verdes, apresentando índice de coloração 2 e 1,57 para os frutos de 20 semanas, estes com índice de coloração variando de 2 a 5. Esses valores foram próximos aos encontrados, para banana 'Prata', por Santos \& Chitarra (1998) e superiores aos apresentados por Vilas-Boas (1995), em média 1,09, para os frutos verdes.

Firmeza - A firmeza foi influenciada, interativamente, pelos fatores armazenamento refrigerado e idade do cacho (Tabela 3).

TABELA 3 - Valores médios de firmeza $(\mathrm{N})$ de bananas 'Prata Anã', provenientes de cachos com 16, 18 e 20 semanas, após a colheita (controle) e armazenadas por 35 dias sob refrigeração.

\begin{tabular}{lccc}
\hline $\begin{array}{c}\text { Armazenamento } \\
\text { refrigerado }\end{array}$ & \multicolumn{4}{c}{ Idade dos cachos (semanas) } \\
\hline Controle (frutos & 6,50 a A & 6,94 a A & 7,32 a A \\
recém-colhidos) & 18 & $\mathbf{2 0}$ \\
35 dias a $10^{\circ} \mathrm{C}$ & 7,25 a A & $6,68 \mathrm{ab} \mathrm{A}$ & $6,39 \mathrm{~b} \mathrm{~A}$ \\
35 dias a $12^{\circ} \mathrm{C}$ & 6,97 a A & $5,64 \mathrm{~b} \mathrm{~B}$ & $3,55 \mathrm{c} \mathrm{C}$ \\
\hline Médias seguidas da mesma letra, maiúscula na horizontal \\
e minúscula na vertical, não diferem entre si pelo teste \\
Tukey, ao nível de significância de 5\%.
\end{tabular}

Os frutos controle (recém-colhidos) apresentaram firmeza semelhante, independentemente de serem provenientes de cachos com 16, 18 e 20 semanas. O mesmo foi observado para os frutos armazenados por 35 dias a $10^{\circ} \mathrm{C}$. Já um amaciamento foi notado em função do avanço da idade dos cachos, para os frutos armazenados por 35 dias a $12^{\circ} \mathrm{C}$.

A temperatura de $10^{\circ} \mathrm{C}$ foi eficaz na prevenção do amaciamento dos frutos de 16 semanas e frutos de 18 semanas. Já a temperatura de $12^{\circ} \mathrm{C}$ foi eficiente na prevenção do amaciamento em frutos de 16 semanas apenas. A temperatura de $10^{\circ} \mathrm{C}$ foi mais efetiva que a temperatura de $12^{\circ} \mathrm{C}$, na prevenção do amaciamento de bananas provenientes de cachos com 20 semanas, embora o amaciamento dos frutos armazenados a $10^{\circ} \mathrm{C}$ tenha sido observado, em comparação ao controle.

$\mathrm{O}$ amaciamento de banana é um indicativo do avanço no seu amadurecimento (BLEINROTH, 1993; CARVALHO et al., 1988; SILVA et al., 1996; VILAS-BOAS et al., 2001), que pode ser controlado pela refrigeração. Os resultados que evidenciaram-se no presente trabalho são condizentes com tal afirmação.

Amido, açúcares e sólidos solúveis totais - A variável amido foi influenciada pelos fatores idade do cacho e armazenamento refrigerado, isoladamente (Tabelas 4 e 5), enquanto as variáveis açúcares e sólidos solúveis totais, pela interação entre ambos fatores (Tabela 6).

Os frutos de 20 semanas apresentaram, em média, teores de amido inferiores aos frutos de 16 e 18 semanas (Tabela 4), o que sugere um mais avançado estado de maturação para os frutos de 20 semanas.

Os frutos armazenados a 10 e $12^{\circ} \mathrm{C}$, por 35 dias, apresentaram, em média, teores de amido semelhantes entre si, embora inferiores aos dos frutos controle, indicando o início da degradação do amido, durante o armazenamento refrigerado, independentemente da temperatura.

TABELA 4 - Valores médios de amido (\%) de bananas 'Prata Anã', após a colheita e armazenadas por 35 dias, sob refrigeração a $10^{\circ} \mathrm{C}$ ou $12^{\circ} \mathrm{C}$, em função da idade do cacho.

\begin{tabular}{ccc}
\hline Idade do cacho (semanas) & Amido $(\boldsymbol{\%})$ & \\
\hline 20 & 19,331 & $\mathrm{~b}$ \\
18 & 21,540 & $\mathrm{a}$ \\
16 & 22,994 & $\mathrm{a}$ \\
\hline
\end{tabular}

Médias seguidas da mesma letra são iguais entre si, pelo teste Tukey, ao nível de significância de 5\%. 
TABELA 5 - Valores médios de amido (\%) de bananas 'Prata Anã', provenientes de cachos com 16, 18 e 20 semanas, após a colheita (controle) e armazenadas por 35 dias sob refrigeração.

\begin{tabular}{lcc}
\hline $\begin{array}{c}\text { Armazenamento } \\
\text { refrigerado }\end{array}$ & Amido $(\%)$ & \\
\hline $\begin{array}{l}\text { Controle (frutos } \\
\text { recém-colhidos) }\end{array}$ & 23,086 & $\mathrm{a}$ \\
35 dias a $10^{\circ} \mathrm{C}$ & 20,468 & $\mathrm{~b}$ \\
35 dias a $12^{\circ} \mathrm{C}$ & 20,312 & $\mathrm{~b}$ \\
\hline
\end{tabular}

Médias seguidas da mesma letra são iguais entre si, pelo teste Tukey, ao nível de significância de 5\%.

TABELA 6 - Valores médios de açúcares solúveis totais (\%) e sólidos solúveis totais (\%) de bananas 'Prata Anã', provenientes de cachos com 16, 18 e 20 semanas, após a colheita (controle) e armazenadas por 35 dias, sob refrigeração.

\begin{tabular}{|c|c|c|c|}
\hline \multirow{3}{*}{$\begin{array}{l}\text { Armazenamento } \\
\text { refrigerado }\end{array}$} & \multicolumn{3}{|c|}{ Idade de cacho (semanas) } \\
\hline & 16 & 18 & 20 \\
\hline & \multicolumn{3}{|c|}{ Açúcares solúveis totais(\%) } \\
\hline $\begin{array}{l}\text { Controle (frutos } \\
\text { recém-colhidos) }\end{array}$ & $0,18 \mathrm{~b} \mathrm{~A}$ & $0,18 \mathrm{~b} A$ & $0,30 \mathrm{~b} \mathrm{~A}$ \\
\hline 35 dias a $10^{\circ} \mathrm{C}$ & 1,93 a B & 3,36 a $\mathrm{A}$ & $1,75 \mathrm{~b} \mathrm{~B}$ \\
\hline \multirow[t]{2}{*}{35 dias a $12^{\circ} \mathrm{C}$} & 1,08 a B & 3,19 a $\mathrm{A}$ & 4,00 a $\mathrm{A}$ \\
\hline & \multicolumn{3}{|c|}{ Sólidos solúveis totais(\%) } \\
\hline $\begin{array}{l}\text { Controle (frutos } \\
\text { recém-colhidos) }\end{array}$ & 9 a $\mathrm{A}$ & $2,19 \mathrm{c} \mathrm{A}$ & $2,25 \mathrm{c} \mathrm{A}$ \\
\hline 35 dias a $10^{\circ} \mathrm{C}$ & 3,90 a $\mathrm{A}$ & $4,25 \mathrm{~b} \mathrm{~A}$ & $5,65 \mathrm{~b} \mathrm{~A}$ \\
\hline 35 dias a $12^{\circ} \mathrm{C}$ & 4,00 a C & 6,05 a B & 9,52 a $A$ \\
\hline
\end{tabular}

Médias seguidas da mesma letra, maiúscula na horizontal e minúscula na vertical, não diferem entre si pelo teste Tukey, ao nível de significância de 5\%.

Os frutos controle (recém-colhidos) apresentaram os mesmos teores de açúcares e sólidos solúveis totais, independentemente da idade dos cachos dos quais foram provenientes. Frutos de 18 semanas, armazenados a $10^{\circ} \mathrm{C}$ e frutos de 18 semanas e frutos de 20 semanas, armazenados a $12^{\circ} \mathrm{C}$, apresentaram os maiores teores açúcares solúveis totais. A idade do cacho não interferiu nos teores de sólidos solúveis dos frutos armazenados a $10^{\circ} \mathrm{C}$. Entretanto, os teores de sólidos solúveis dos frutos armazenados a $12^{\circ} \mathrm{C}$ foram tão menores quanto mais jovens os cachos.

$\mathrm{O}$ armazenamento refrigerado determinou, independentemente da temperatura, incrementos nos teores de açúcares e sólidos solúveis totais, coerentes com a degradação do amido, à exceção da variável açúcares solúveis totais, para os frutos de 16 semanas.

A conversão de amido em açúcares, com conseqüente acúmulo de sólidos solúveis totais, consiste num importante evento durante o amadurecimento de bananas, responsável por modificações desejáveis, no seu sabor e textura (VILAS-BOAS et al., 2001). O armazenamento refrigerado visa retardar tais alterações, que diminuiriam a vida de prateleira do produto, sendo que o estádio de maturação dos frutos influencia sua vida pós-colheita (SANTOS \& CHITARRA, 1998).

pH e acidez titulável - $\mathrm{O}$ pH e a acidez titulável foram influenciados pelos fatores idade do cacho e armazenamento refrigerado (Tabela 7).

TABELA 7 - Valores médios de pH e acidez titulável (\%) de bananas 'Prata Anã', provenientes de cachos com 16, 18 e 20 semanas, após a colheita (controle) e armazenadas por 35 dias, sob refrigeração.

\begin{tabular}{|c|c|c|c|}
\hline \multirow{2}{*}{$\begin{array}{c}\text { Armazenamento } \\
\text { refrigerado }\end{array}$} & \multicolumn{3}{|c|}{ Idade de cacho (semanas) } \\
\hline & 16 & $\begin{array}{l}18 \\
\mathrm{pH}\end{array}$ & 20 \\
\hline $\begin{array}{l}\text { Controle (frutos } \\
\text { recém-colhidos) }\end{array}$ & 5,54 a A & 5,46 a $\mathrm{A}$ & 5,48 a $\mathrm{A}$ \\
\hline 35 dias a $10^{\circ} \mathrm{C}$ & 5,53 a $\mathrm{A}$ & 5,45 a $\mathrm{A}$ & 5,25 a $\mathrm{A}$ \\
\hline \multirow[t]{2}{*}{35 dias a $12^{\circ} \mathrm{C}$} & 5,35 a $\mathrm{A}$ & 5,22 b A & 5,12 b B \\
\hline & \multicolumn{3}{|c|}{ Acidez titulável (\%) } \\
\hline $\begin{array}{l}\text { Controle (frutos } \\
\text { recém-colhidos) }\end{array}$ & 0,22 a $A$ & $0,24 \mathrm{~b} \mathrm{~A}$ & $0,23 \mathrm{~b} \mathrm{~A}$ \\
\hline 35 dias a $10^{\circ} \mathrm{C}$ & 0,23 a $\mathrm{A}$ & $0,27 \mathrm{~b} \mathrm{~A}$ & $0,23 \mathrm{~b} \mathrm{~A}$ \\
\hline 35 dias a $12^{\circ} \mathrm{C}$ & 0,29 a B & 0,34 a $\mathrm{A}$ & 0,36 a $\mathrm{A}$ \\
\hline
\end{tabular}

Médias seguidas da mesma letra, maiúscula na horizontal e minúscula na vertical, não diferem entre si pelo teste Tukey, ao nível de significância de 5\%.

A idade do cacho não interferiu no $\mathrm{pH}$ e acidez titulável dos frutos controle e daqueles armazenados, por 35 dias, a $10^{\circ} \mathrm{C}$. Já os frutos de 16 semanas apresentaram pH e acidez titulável superior e inferior, respectivamente, a dos frutos de 20 semanas e acidez titulável inferior a dos frutos de 18 semanas, após 35 dias de armazenamento a $12^{\circ} \mathrm{C}$. A temperatura de $10^{\circ} \mathrm{C}$ foi eficaz em prevenir alterações significativas no $\mathrm{pH}$ e acidez titulável dos frutos de 16,18 e 20 semanas, enquanto a temperatura de $12^{\circ} \mathrm{C}$ preveniu alterações apenas nos frutos de 16 semanas, durante os 35 dias de armazenamento.

$\mathrm{O}$ pH e acidez titulável dos frutos de 18 semanas e frutos de 20 semanas, submetidos à temperatura de $12^{\circ} \mathrm{C}$, 
foram inferior e superior, respectivamente, em relação à dos frutos mantidos à temperatura de $10^{\circ} \mathrm{C}$ e dos frutos controle, devido a seu estado mais avançado de maturação. A acidificação da polpa de banana é uma modificação natural, observada ao longo do seu amadurecimento (VILAS-BOAS, 2001).

Os valores de $\mathrm{pH}$ e acidez titulável, que observaramse este trabalho, são concordantes com os publicados por outros autores, para diferentes cultivares de banana, verdematuras (BLEINROTH, 1995; BOTREL et al., 2002; FERNANDES et al., 1979; SGARBIERI \& FIGUEIREDO, 1966), entretanto, são discordantes dos apresentados por Santos \& Chitarra (1998), ao trabalharem com banana 'Prata', em função da idade do cacho.

\section{CONCLUSÕES}

Não houve incidência de "chilling" nos frutos provenientes de cachos com 16, 18 e 20 semanas, após 35 dias de refrigeração a 10 e $12^{\circ} \mathrm{C}$.

Bananas 'Prata Anã', provenientes de cachos de 20 semanas, visando o armazenamento refrigerado por 35 dias, não são recomendáveis, visto que os frutos tiveram o seu amadurecimento iniciado durante esse período, sob refrigeração.

As temperaturas de 10 e $12^{\circ} \mathrm{C}$ são eficientes durante 35 dias de armazenamento, na contenção do amadurecimento de bananas provenientes de cachos com 16 e 18 semanas, porém, a temperatura de $12^{\circ} \mathrm{C}$ é economicamente mais viável.

\section{REFERÊNCIAS BIBLIOGRÁFICAS}

ASSOCIATION OF OFFICIAL ANALYTICAL CHEMISTRY. Official methods of analysis of the Association of Official Analytical Chemistry. 12. ed. Washington, DC, 1992.

AYUB, R. A. Estudos para determinação do ponto de colheita da banana 'Prata': musa AAB subgrupo Prata. 1990. 52 f. Dissertação (Mestrado em Fitotecnia) Universidade Federal de Viçosa, Viçosa, 1990.

BLEINROTH, E. W. Matéria prima. In: INSTITUTO DE TECNOLOGIA DEALIMENTOS. Bananas: cultura, matériaprima, processamento e aspectos econômicos. 2. ed. Brasília, DF: Embrapa, 1995. (Série Fruta do Brasil).

BLEINROTH, E. W. Matéria prima. In: MEDINA, J. C.; BLEINROTH, E. W.; MARTIN, Z. J. de; TRAVAGLINI, D. A.; OKADA, M.; QUAST, D. G.; HASHIZUMED, T.;
MORETTI, V. A.; BICUDO NETO, L. de C.; ALMEIDA, L. A. S. B.; RENESTO, O. V. Banana: cultura, matéria-prima, processamento e aspectos econômicos. 2. ed. Campinas: ITAL, 1993. 302 p. (Frutas tropicais, 3).

BOTREL, N.; FREIRE, M. J.; VASCONCELOS, R. M. de; BARBOSA, H. T. G. Inibição do amadurecimento da banana "Prata Anã" com a aplicação do 1-Metilciclopropeno. Revista Brasileira de Fruticultura, Jaboticabal, v. 24, n. 1, p. 53-56, abr. 2002.

CANCIAN, A.; CARVALHO, V. D. Manejo pós-colheita da banana. Informe Agropecuário, Belo Horizonte, v. 6, n. 63, p. 47-53, jul. 1980 .

CARVALHO, H. A.; CHITARRA, M. I. F.; CARVALHO, H. S. de. Banana 'Prata' amadurecida sob umidade relativa elevada. Pesquisa Agropecuária Brasileira, Brasília, v. 23, n. 12, p. 1331-1338, 1988.

DISCHE, Z. General color reactions. In: WHISTLER, R. L.; WOLFRAN, M. L. Carbohydrate chemistry. New York: Academic, 1962. p. 477-512.

FERNANDES, K. M.; CARVALHO, V. D.; CAL-VIDAL, J. Physical changes during ripening of Silver bananas. Journal of Food Science, Chicago, v. 44, n. 4, p. 1254-1255, 1979.

LICHTEMBERG, L. A. Pós-colheita de banana. In: SIMPÓSIO NORTE MINEIRO SOBRE A CULTURA DA BANANA, 2001, Nova Porteirinha, MG. Palestras... Nova Porteirinha: Epamig-CTNM, 2001. p. 105-130.

LIMA, L. C.; CASTRO, M. V.; DIAS, M. S. C.; MARTINS, R. N.; SILVA, D. F. P.; COSTA, S. M.; RIBEIRO JÚNIOR, P. M.; BRESISNSKI, T. L. Conservação pós-colheita de banana 'Prata-anã' produzida na região Norte de Minas Gerais. In: SIMPÓSIO NORTE MINEIRO SOBRE A CULTURA DA BANANA, 2001, Nova Porteirinha, MG. Resumos... Nova Porteirinha: Epamig-CTNM, 2001. p. 272-275.

MORRELLI, K. I.; PIERCE, B. M. H.; KADER, A. A. Genotypic variation in chilling sensitivity of mature-green bananas and plantains. Hortechnology, Davis, Apr./June 2003.

SANTOS, J. E. da S.; CHITARRA, M. I. Relação entre a idade do cacho de banana 'Prata' à colheita e a qualidade dos frutos após a colheita. Pesquisa Agropecuária Brasileira, Brasília, v. 33, n. 9, p. 1475-1480, set. 1998. 
SGARBIERI, V. C.; FIGUEIREDO, I. B. Estudo bioquímico de algumas variedades de banana cultivadas no Brasil. Coletânea Instituto de tecnologias de Alimentos do ITAL, Campinas, v. 1, n. 1, p. 299-322, 1966.

SILVA, A. P.; EVANGELISTA, R. M.; VIEITES, R. L. Uso de amido e saco de polietileno na conservação pós-colheita de bananas, armazenadas sob refrigeração. Revista Brasileira de Fruticultura, Cruz das Almas, v. 18, n. 1, p. 31-42, abr. 1996.

VILAS-BOAS, E. V. de B. Modificação pós-colheita de bananas 'Prata' (Musa acuminata x Musa balbisiana Grupo AAB) ã-irradiada. 1995. 73 f. Dissertação (Mestrado em
Ciências dos Alimentos) - Universidade Federal de Lavras, Lavras, 1995.

VILAS-BOAS, E. V. de B.; ALVES, R. E.; FIGUEIRAS, H. A. C.; MENEZES, J. B. Banana: pós-colheita. Embrapa Informação Tecnológica, Brasília, v. 16, p. 15-19, 2001.

WILLS, R. H. Post-harvest technology of banana and papaya in ASEAN: an overwien. ASEAN Food journal, [S.1.], v. 5, n. 2, p. 47-50, 1990.

WILLS, R. H.; McGLASSON, B.; GRAHAM, D.; JOICE. Postharvest: an introduction to the physiology and handling of fruit, vegetables \& ornamentals. Sydney: [s.n.], 1998. 